\title{
Hierarchical MnOx/ZSM-5 as Heterogeneous Catalysts in Conversion of Delignified Rice Husk to Levulinic Acid
}

\author{
Yuni Krisyuningsih Krisnandi ${ }^{1,}$, Dita Arifa Nurani ${ }^{1}$, Anastasia Agnes ${ }^{1}$, Ralentri Pertiwi ${ }^{1}$, \\ Noer Fadlina Antra ${ }^{1}$, Alika Rizki Anggraini ${ }^{1}$, Anya Prilla Azaria ${ }^{1}$, and Russell Francis Howe ${ }^{2}$ \\ ${ }^{1}$ Department of Chemistry, Faculty of Mathematics and Natural Sciences, Universitas Indonesia, Depok 1642, Indonesia \\ ${ }^{2}$ Department of Chemistry, University of Aberdeen, Meston Walk, Aberdeen AB24 3UE, Scotland, United Kingdom
}

\author{
*Corresponding author: \\ email:yuni.krisnandi@sci.ui.ac.id
}

Received: September 17, 2017

Accepted: June 4, 2018

DOI: $10.22146 /$ ijc. 28332

\begin{abstract}
Hierarchical ZSM-5 zeolite was synthesized using a double-template method using TPAOH and PDDA as templates, while microporous ZSM-5 was also prepared using only TPAOH as a template. The syntheses then were followed by impregnation with $\mathrm{Mn}(\mathrm{II})$ c.a. $2 \mathrm{wt} . \%$ and calcination at $550{ }^{\circ} \mathrm{C}$ to obtain $\mathrm{MnOx} / \mathrm{ZSM}-5$ zeolite catalysts. Extensive characterization of the zeolite catalysts was performed using XRD, SEM, AAS, EDX, FTIR, and BET measurement. The characterization showed that hierarchical or mainly mesoporous ZSM-5 was successfully synthesized, having added features compared to the microporous counterpart. The catalysts then were used in conversion reaction of delignified rice husk to levulinic acid, a platform chemical. As a comparison, a certain amount of $\mathrm{MnCl}_{2} \cdot \mathrm{H}_{2} \mathrm{O}$ was used as a homogeneous catalyst in a similar reaction. The product of the reaction was separated and analyzed with HPLC. It showed that $8 \mathrm{~h}$ was the optimum condition for the conversion, with hierarchical MnOx/hi_ZSM-5 catalyst gave the highest amount of levulinic acid (\%Y of 15.83\%), followed by microporous MnOx/mi_ZSM-5 (\%Y of 10\%). The \% yield of levulinic acid using homogeneous Mn(II) catalyst (\%Y of $8.86 \%$ ) gave more charcoal as a product. Meanwhile, the stability of the zeolite catalysts after the reaction has also been investigated, mainly by analyzing the FTIR spectra and EDX data of the used catalysts after separated and calcined at $550{ }^{\circ} \mathrm{C}$. From the analysis, some of the silica and alumina are leached from the framework, as well as the manganese oxide due to acidic condition at the beginning of the reaction. Nevertheless, it can be concluded that the conversion took place as the interaction between the cellulose and either $\mathrm{MnOx}$ in zeolites or $\mathrm{Mn}^{2+}$ ions in the solution, with the support of porous ZSM-5 framework. Hierarchical system somehow assists the ZSM-5 structure stays intact.
\end{abstract}

Keywords: hierarchical ZSM-5; biomass conversion; levulinic acid; rice husk cellulose; catalyst stability

\section{- INTRODUCTION}

In general, heterogeneous catalyst offers the greatest potential due to the simple, easy separation, reusable, and limited waste disposal [1]. Zeolite and zeolitic materials have been used widely as heterogeneous catalysts. When using zeolite as support or active sites, it is expected that the reactions taking place within the pores, and/or on the surface of the zeolite, which can increase the selectivity of the catalyst [2]. Microporous zeolites have been widely used in industry as heterogeneous catalysts, especially as solid acid catalysts in the fields of oil refining and petrochemistry. The relatively small and sole micropores $(0.5-2 \mathrm{~nm})$ in zeolites significantly influence the mass transport to and from the active sites located in micropores. From this case, the hierarchical zeolite that has mesoporous and microporous characters is needed, in which their good properties e.g. good mass transfer and high thermal stability are kept in order to increase the activity of this zeolite [3]. 
In the past ten years, the study of biomass conversions to biofuel has given much attention to reducing the utilization of fossil fuel as primary energy sources [3]. Biomass consists of lignocellulosic compounds i.e. cellulose, hemicellulose, and lignin. In Indonesia, rice husk becomes potential to be used as feedstock of biomass conversion, representing agricultural waste. There are three main organic components found in rice husk i.e. $28.6 \%$ cellulose, $28.6 \%$ hemicellulose, and $24.4 \%$ lignin. Besides those organic components, there is also $18.4 \mathrm{wt} . \%$ extractive matter [4].

National Renewable Energy Laboratory USA has identified levulinic acid (LA) as one of the key-sugarderived platform chemicals that can be produced from biomass, with huge potential uses such as solvents, resin, flavors, antifreeze and animal feed [5]. Levulinic acid can be produced from lignocellulose dissolved in the dilute acid catalyst as a homogeneous system, such as sulphuric acid and hydrochloric acid [6]. Therefore, the development of heterogeneous catalysts in lignocellulosic conversion has risen significantly [7-8] for example, more valuable chemical such as $\gamma$-valerolactone and ethyl levulinate can be produced in LA conversion [9-10].

The studies conducted on the synthesis of levulinic acid using solid acid catalysts such as Amberlite IR-120, Nafion SAC-13, clay and zeolite (e.g. HY, ZSM-5) has been reviewed by Rackemann et al. [11]. The levulinic acid of $5 \mathrm{wt}$.\% was obtained when ZSM- 5 used as a catalyst using 5-(Hydroxymethyl)furfural (HMF) as feed at $\mathrm{T} 116^{\circ} \mathrm{C}$ for $2 \mathrm{~h}$ reaction. Recently, using microporous $\mathrm{MnOx} / \mathrm{ZSM}-5$ as a catalyst through Fenton-like reaction, Chen et al. [12] reported the degradation of pure cotton cellulose to mainly HMF, and LA as a side product. There are three stages in cellulose degradation process, including breakage inter and intramolecular hydrogen bonds, activation effect of the Fenton-like regent, and dehydration of glucose followed by formation of 5-HMF and levulinic acid. The optimum reaction condition was found to be at $403 \mathrm{~K}, \mathrm{H}_{3} \mathrm{PO}_{4} 55 \%, \mathrm{H}_{2} \mathrm{O}_{2} 0.5 \mathrm{~mL}$, catalyst $0.1 \mathrm{~g}$ and reaction time $5 \mathrm{~h}$ giving the highest 5-HMF yield.

Based on results reported by Chen et al. [12], the aim of our work is to investigate the use of hierarchical and microporous ZSM-5 decorated with manganese oxide
$(\mathrm{MnOx})$ as the catalysts on delignified rice husk conversion to levulinic acid. It is expected that additional mesoporous character in the hierarchical ZSM-5 would increase the catalytic activity by giving the reactant more access to the active sites of the catalyst. Furthermore, this catalyst may allow hydrolysis and dehydration of lignocellulosic materials to be implemented in a single reaction stage. The stability of these catalysts after the reaction was also studied.

\section{- EXPERIMENTAL SECTION}

\section{Materials}

Indonesian rice husk waste was obtained from Tambun Rengas, Cakung, Jakarta Timur, Indonesia. The chemicals used in experiment were analytical grade as follows: phosphoric acid (89.0\%), hydrogen peroxide (30.0\%), sulphuric acid (96.0\%), sodium hydroxide (99.0\%), ethanol (95.0\%) and manganese chloride (99.0\%) were obtained from Merck; sodium aluminate (99.0\%), tetraorthosilicate (TEOS, 98.0\%), tetrapropylammonium hydroxide (TPAOH, $1.0 \mathrm{M}$ ), and polidialydimethyl ammonium chloride (PDDA, 35.0\%) were all obtained from Sigma Aldrich.

\section{Instrumentation}

The ZSM-5 and MnOx/ZSM-5 catalysts were characterized using various solid state characterization techniques such as X-ray Diffraction (XRD), Fourier Transform Infrared (FTIR), Brunauer-Emmett-Teller (BET) method, Scanning Electron Microscope (SEMEDAX), and Atomic Absorption Spectroscopy (AAS). Infrared spectra were observed using an Alpha-Bruker FTIR spectrometer with a $4 \mathrm{~cm}^{-1}$ resolution and 256 scans. A solid was pressed into a pellet and be treated on a vacuum system for $3 \mathrm{~h}$. The XRD patterns were collected using Rigaku diffractometer (MiniFlexII/AP) at $40 \mathrm{kV}, 30 \mathrm{~mA}, \mathrm{Cu}_{\mathrm{Ka}}$, in $5-50^{\circ} 2 \theta$ range. Nitrogen physisorption isotherms at $-195.7{ }^{\circ} \mathrm{C}$ were measured with Quantachrome instrument. The specific surface area was estimated according to the BET method, while pore volume was calculated from the $\mathrm{BJH}$ desorption curve. SEM images were taken with SEM FEI INSPECT $\mathrm{F} 50$ at $20 \mathrm{kV}$ and Si/Al were measured semi quantitatively 
with EDAX system. Mn-content was determined using AAS-spectrometry.

\section{Procedure}

\section{Preparation of catalysts}

Hierarchical ZSM-5 was synthesized using the method as reported by Wang et al. [3] with some modification by Krisnandi et al. [13]. The gel of hierarchical ZSM-5 was prepared from a homogeneous mixture with molar composition of $1 \mathrm{Al}_{2} \mathrm{O}_{3}: 64.35 \mathrm{SiO}_{2}: 10.08$ (TPA) ${ }_{2} \mathrm{O}$ : $3571.66 \mathrm{H}_{2} \mathrm{O}$. The mixture was stirred for $3 \mathrm{~h}$ at $100{ }^{\circ} \mathrm{C}$, then $1.0 \mathrm{~g}$ of PDDA was added and stirred for $15 \mathrm{~h}$. Subsequently, the mixture was transferred to a Teflonfined autoclave for further crystallization at $170{ }^{\circ} \mathrm{C}$ for 6 days. The product was filtered, washed, dried, calcined, and labeled as Hi_ZSM-5. The microporous ZSM-5 was synthesized using a similar method as hierarchical without PDDA as a template. It was named Mi_ZSM-5.

Hierarchical MnOx/ZSM-5 was prepared using the impregnation method. $1.7 \mathrm{~mL}$ of $0.214 \mathrm{M} \mathrm{MnCl}_{2} \cdot 4 \mathrm{H}_{2} \mathrm{O}$ in $\mathrm{H}_{2} \mathrm{O}$ was added to $1.0 \mathrm{~g}$ of hierarchical ZSM-5 in order to achieve $2.0 \%$ loading of $\mathrm{Mn}$ (II). The mixture was stirred for $24 \mathrm{~h}$, dried, and then calcined at $550{ }^{\circ} \mathrm{C}$ for $3 \mathrm{~h}$ to obtain MnOx/ZSM-5. All obtained catalysts were characterized using XRD, AAS, FTIR, BET, and SEM.

\section{Pre-treatment of rice husk}

Indonesian rice husk was milled using a grinder and sieved to obtain particle size between 315 and $710 \mu \mathrm{m}$. Rice husk then extracted with $n$-hexane and ethanol mixtures as solvents using soxhlet for $6.5 \mathrm{~h}$ (dewax process). In order to reduce lignin content in the lignocellulosic substrate, rice husk which has been dewaxed was treated with $20 \%$ of $\mathrm{NaOH}$ at $55{ }^{\circ} \mathrm{C}$ for $1.5 \mathrm{~h}$ (delignification process). The residue obtained from the delignification process was then filtered and washed with distilled water. Both raw and dignified Indonesian rice husk were characterized using FTIR and XRD. The composition of lignin, holocellulose, and $\alpha$-cellulose of Indonesian rice husk were determined using Klason Lignin [14-16].

\section{Catalytic test}

Conversion reaction, modified from [12], was carried out by adding $1.0 \mathrm{~g}$ of delignified Indonesian rice husk as substrate and $0.1 \mathrm{~g}$ of zeolite catalyst to a mixture of $20 \mathrm{~mL}$
$\mathrm{H}_{3} \mathrm{PO}_{4} 40 \%(\mathrm{v} / \mathrm{v}), 0.5 \mathrm{~mL} \mathrm{H} \mathrm{H}_{2} \mathrm{O}_{2} 30 \%$ (v/v) into threenecked round bottom flask connected to condenser and immersed into oil bath to maintain the reaction temperature at $100^{\circ} \mathrm{C}$. After a certain reaction time, the sample was cooled immediately in an ice bath to quench the reaction, then the filtrate was separated from solid for product analysis. The solid part was then analyzed using EDX and FTIR for catalyst stability study. Similar reaction condition was applied for the reaction using a homogeneous catalyst, in which $0.07 \mathrm{~g}$ of $\mathrm{MnCl}_{2} \cdot 4 \mathrm{H}_{2} \mathrm{O}$ was used as a catalyst. As a control, reaction without any catalyst was performed by using $1.0 \mathrm{~g}$ of delignified rice husk as feed.

\section{Analysis of products}

The HPLC-analysis was performed on a Rezex ${ }^{\mathrm{TM}}$ ROA-Organic Acid H+ (8\%) equipped with a UV-Visible detector (SPD-20A, Shimadzu) at $220 \mathrm{~nm}$ and a column oven (CTO-10ASvp, Shimadzu) at $35{ }^{\circ} \mathrm{C}$, using LC20AB HPLC system (Shimadzu, Japan). Sulphuric acid $0.00025 \mathrm{M}$ as eluent, was pumped at a flow rate of 0.6000 $\mathrm{mL} / \mathrm{min}$. The \% yield of Levulinic acid (LA) was calculated using the equation 1.

$\%$ yield L.A $=\frac{\text { [weight of L.A] }}{\text { [weight of cellulose }{ }^{*} \text { in delignified rice husk] }} \times 100 \%$

${ }^{*}$ weight of cellulose was determined from wt.\% cellulose after delignification.

\section{- RESULTS AND DISCUSSION}

\section{Preparation and Characterization of Catalysts}

The as-synthesized microporous and hierarchical ZSM-5 were prepared using single and double organictemplate method (i.e. TPAOH and PDDA), respectively. $\mathrm{TPAOH}$ acts as a structure directing agent of the microporous ZSM-5 framework and the PDDA polycation as meso-template because it is easily dissolved in water, stable at the hydrothermal temperature $\left(170^{\circ} \mathrm{C}\right)$, and positively-charged that will interact with the negative charge from zeolite framework [17]. Both organic templates were completely removed after calcination at $550^{\circ} \mathrm{C}$, as shown by infrared spectra in Fig. 1 where after calcination the peaks at $2950-2850 \mathrm{~cm}^{-1}$ and at 1450 $1350 \mathrm{~cm}^{-1}$ assigned for $-\mathrm{C}-\mathrm{H}$ stretching and $-\mathrm{C}-\mathrm{H}$ bending 

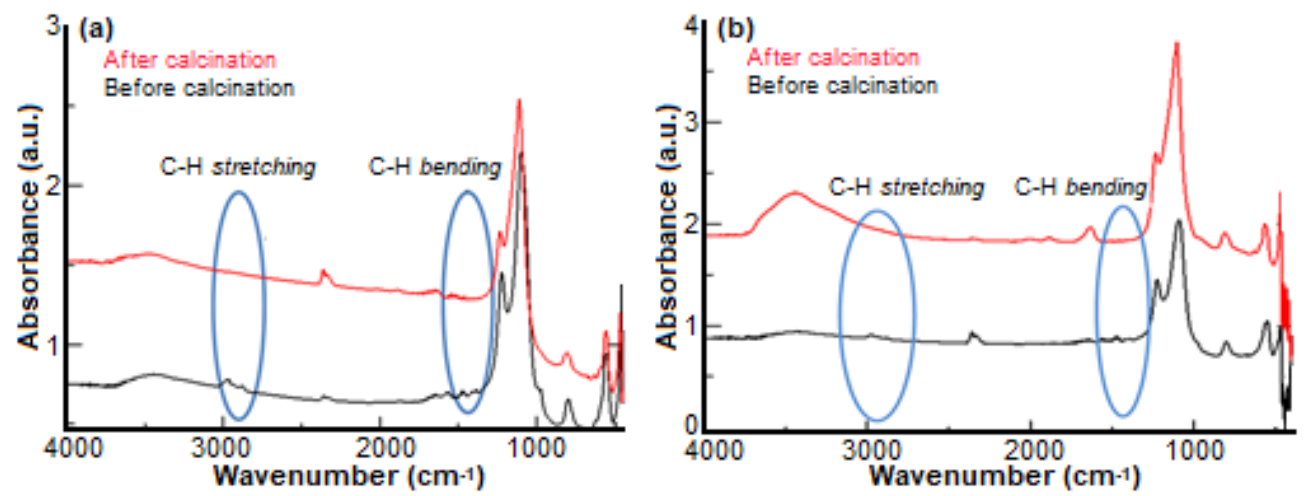

Fig 1. FTIR spectra of (a) Mi_ZSM-5 and (b) Hi_ZSM-5 before and after calcination

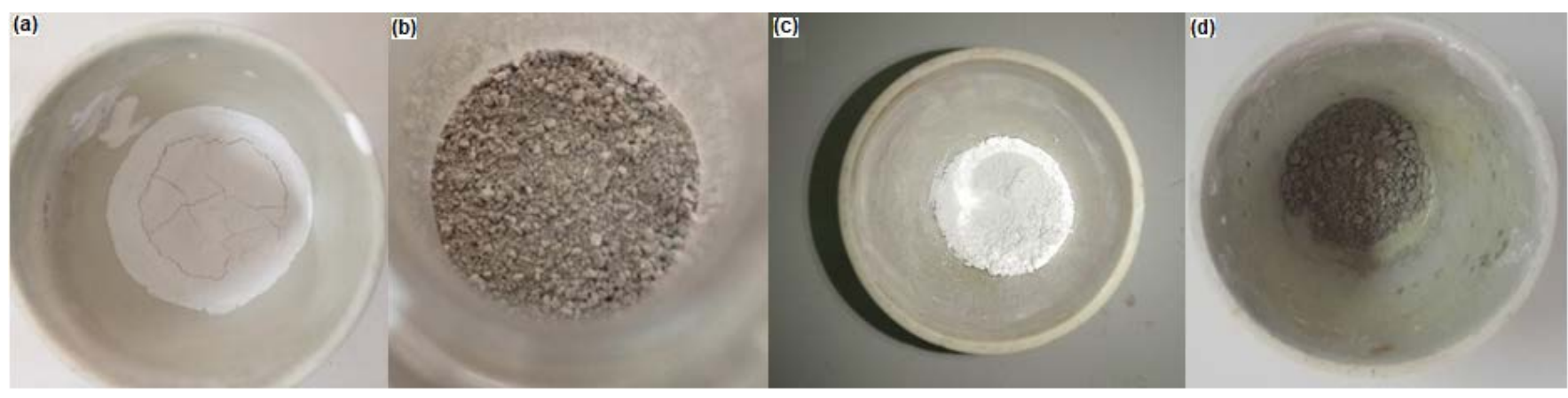

Fig 2. Photographs of as-synthesized: (a) Mi_ZSM-5, (b) Hi_ZSM-5, and their respective MnOx/ZSM-5 (c and d)

from the organic templates are disappeared, giving white powdered Mi_ZSM-5 (Mi = microporous) and Hi_ZSM$5(\mathrm{Hi}=$ hierarchical $)$ material. $\mathrm{MnOx} / \mathrm{ZSM}-5$ was a brown colored powder with Mn content of c.a. 2 wt.\% (Fig. 2).

The X-ray diffraction pattern of Mi_ZSM-5 and Hi_ZSM-5 are shown in Fig. 3(a) and 3(c), which in agreement with that reported previously [18] as well as in the literature [19]. They include two distinct peaks at $2 \theta=$ $7-10^{\circ}$ and three peaks at $2 \theta=22-25^{\circ}$. The sharp and narrow peaks of both micro- and hierarchical- ZSM-5 indicate that they have high crystallinity. Furthermore, the structure of Hi_ZSM-5 and Mi_ZSM-5 are not significantly altered after decoration with $\mathrm{MnOx}$ ( $2 \%$ of Mn species) by impregnation method (Fig. 3(b) and 3(d)). However, the peaks related to $\mathrm{MnOx}$ are hardly observed, maybe due to a small amount of them.

The morphology of microporous and hierarchical ZSM- 5 crystals, as characterized using SEM, are shown in Fig. 4. It is shown that although the Mi_ZSM-5 has rather a round end (Fig. 4(a)), both ZSM-5 crystals have the coffin-like shape of MFI structure [20]. Furthermore, as

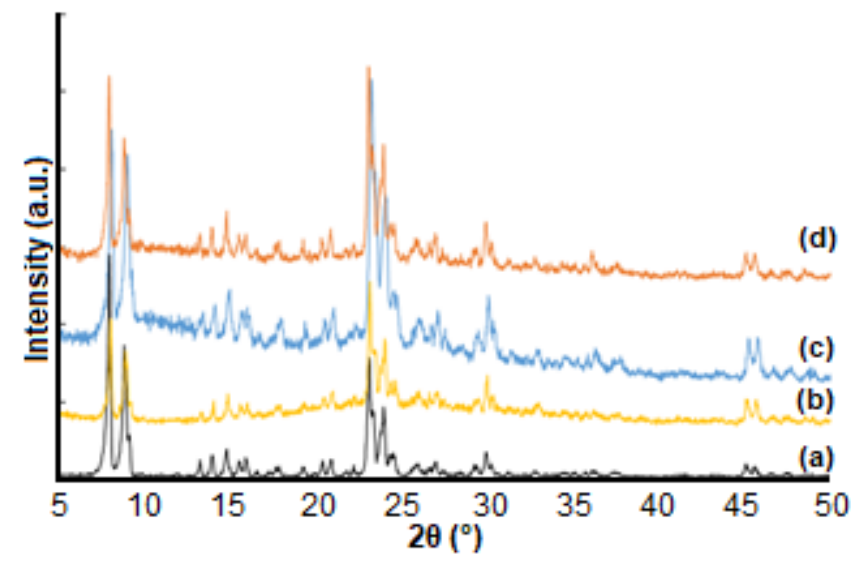

Fig 3. XRD Pattern of (a) Mi_ZSM-5, (b) MnOx/ZSM5, (c) Hi_ZSM-5 and (d) MnOx/Hi_ZSM-5

seen in Fig. 4(b), the crystal morphology of Hi_ZSM-5 is different from the microporous Mi_ZSM-5, in which it has a rough surface, indicative of hierarchical zeolites [20-21].

The surface properties of Mi_ZSM-5 and Hi_ZSM5 have been analyzed and the results are summarized in Table 1 and Fig. 5. The total surface areas of Mi_ZSM-5 and Hi_ZSM-5 are $294 \mathrm{~m}^{2} \mathrm{~g}^{-1}$ and $364.6 \mathrm{~m}^{2} \mathrm{~g}^{-1}$, respectively. 


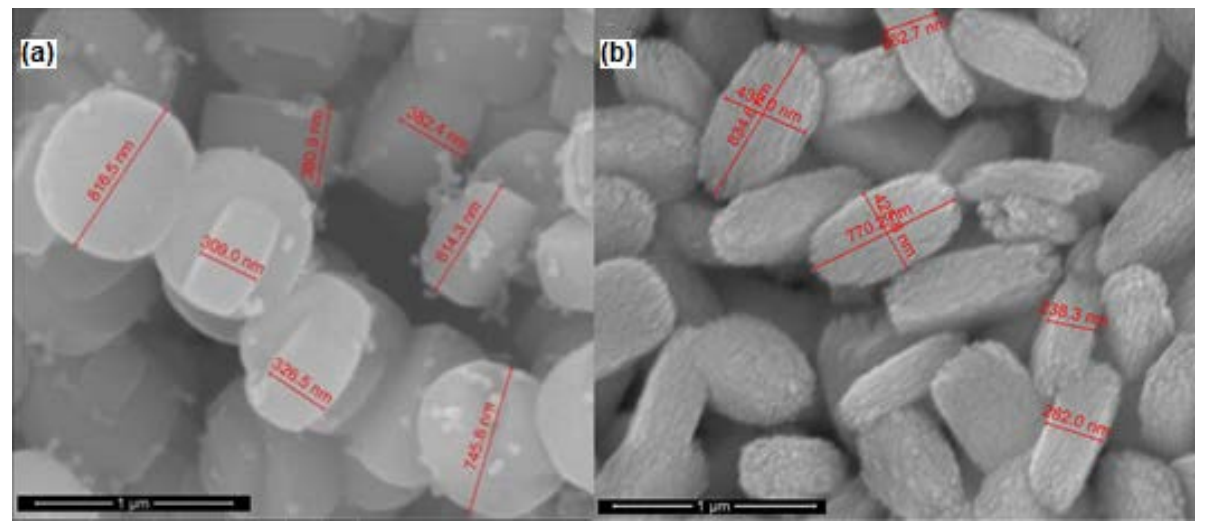

Fig 4. SEM images from (a) Hi_ZSM-5 and (b) Mi_ZSM-5

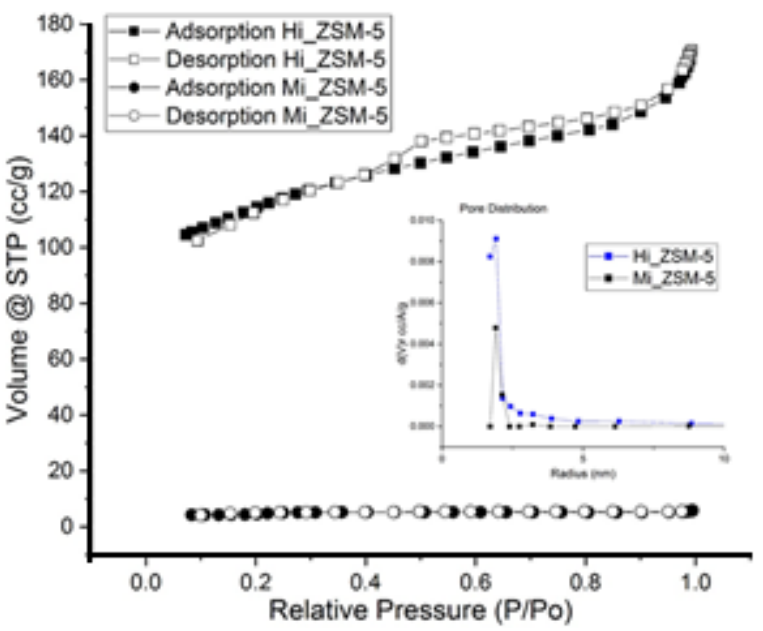

Fig 5. Isotherm adsorption-desorption of Mi_ZSM-5 and Hi_ZSM-5. Inset: BJH desorption curves to measure the pore radius distribution

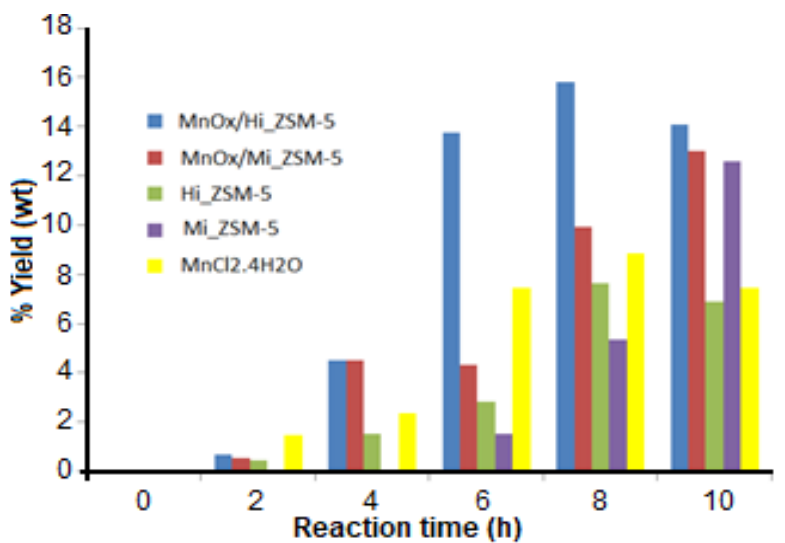

Fig 6. \% Yield of levulinic acid from the conversion of delignified rice husk using ZSM-5 catalysts at condition: $1.0 \mathrm{~g}$ of delignified Indonesian rice husk, $0.1 \mathrm{~g}$ of catalyst, $40 \%(\mathrm{v} / \mathrm{v}) \mathrm{H}_{3} \mathrm{PO}_{4}, 20 \%(\mathrm{v} / \mathrm{v}) \mathrm{H}_{2} \mathrm{O}_{2}$, at $373 \mathrm{~K}$ for $10 \mathrm{~h}$. $\mathrm{MnCl}_{2} \cdot 4 \mathrm{H}_{2} \mathrm{O}$ used: $0.07 \mathrm{~g}$

Table 1. Physicochemical properties of Hi_ZSM-5 and Mi_ZSM-5

\begin{tabular}{ccccccccc}
\hline Sample & $\begin{array}{c}\text { Total SA } \\
\left(\mathrm{m}^{2} \mathrm{~g}^{-1}\right)\end{array}$ & $\begin{array}{c}\text { SA meso }^{\mathrm{c}} \\
\left(\mathrm{m}^{2} \mathrm{~g}^{-1}\right)\end{array}$ & $\begin{array}{c}\text { SA micro }^{\mathrm{b}} \\
\left(\mathrm{m}^{2} \mathrm{~g}^{-1}\right)\end{array}$ & $\begin{array}{c}\text { Total vol. } \\
\left(\mathrm{cm}^{3} \mathrm{~g}^{-1}\right)\end{array}$ & $\begin{array}{c}\text { Vol. micro }^{\mathrm{b}} \\
\left(\mathrm{cm}^{3} \mathrm{~g}^{-1}\right)\end{array}$ & $\begin{array}{c}\text { Vol. meso }^{\mathrm{c}} \\
\left(\mathrm{cm}^{3} \mathrm{~g}^{-1}\right)\end{array}$ & $\begin{array}{c}\text { Pore diameter } \\
(\mathrm{nm})\end{array}$ & Si/Al $^{\mathrm{e}}$ \\
\hline Mi_ZSM-5 & 294 & 16.16 & 277.84 & 0.1620 & 0.1358 & 0.029 & 1.909 & 32.4 \\
Hi_ZSM-5 & 364.6 & 53.62 & 310.98 & 0.2586 & 0.160 & 0.098 & $1.922 ; 3.200$ & 26.29 \\
\hline
\end{tabular}

$\mathrm{A}=\mathrm{BET}$ measurement, $\mathrm{b}=\mathrm{t}$-plot analysis, $\mathrm{c}=\mathrm{a}-\mathrm{b}, \mathrm{d}=\mathrm{BJH}$ desorption, $\mathrm{e}=\mathrm{EDX}$ measurement

The distribution of pore diameter of Mi_ZSM-5 is in agreement with conventional ZSM-5 and falls into the microporous materials region $(\sim<2 \mathrm{~nm})$ [2]. Meanwhile, the Hi_ZSM-5 has two pore diameter distribution, 1.922 and $3.200 \mathrm{~nm}$. The second pore distribution is higher than $2.0 \mathrm{~nm}$, which can be categorized as mesoporous type [2]. Therefore, it is confirmed that Hi_ZSM-5 has two types of porosity or hierarchical pores. The isotherm adsorption- desorption curve of Hi_ZSM-5 also gives evidence of mesoporosity with the appearance of the hysteresis loop in $0.4-0.9 \mathrm{P} /$ Po region.

\section{Pre-treatment of Rice Husk}

Delignification of rice husk in this work resulted in the decrease of lignin to $18.2 \%$. However, some $\alpha$ cellulose is also decreased, as shown in Table 2. This could be due to some $a$-cellulose molecules are strongly 
bonded to lignin, so that they also removed during delignification with a strong base, $\mathrm{NaOH}$. The weight fraction of $\alpha$-cellulose after delignification (25.96\%) then was used for calculating the amount of $\alpha$-cellulose in the substrate, so that the \% yield of Levulinic Acid could be determined.

\section{Conversion of Delignified Rice Husk to Levulinic Acid}

The catalytic test was carried out on conversion of delignified rice husk to levulinic acid (LA) using $\mathrm{MnOx} / \mathrm{Hi} Z \mathrm{ZSM}-5$. For comparison purpose, the reaction using Hi_ZSM-5, MnOx/Mi_ZSM-5 and MnOx/ZSM-5 catalysts were also conducted. Fig. 6 summarizes the $\%$ yield of LA obtained from the reaction using those catalysts.

It can be seen that the optimum \% yield for each reaction was varied. Fig. 6 shows that the highest \% yield $(15.83 \%)$ of LA is in $8 \mathrm{~h}$ reaction at $100{ }^{\circ} \mathrm{C}$ using
Table 2. Properties of rice husk

\begin{tabular}{ccc}
\hline Rice Husk & \% lignin & \% a-cellulose \\
\hline Raw & 35.64 & 38.33 \\
After delignification & 18.42 & 25.96 \\
\hline
\end{tabular}

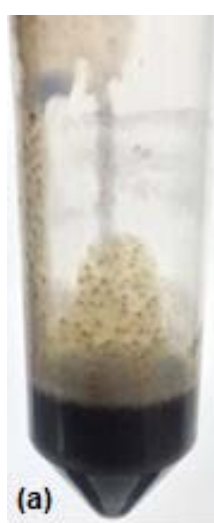

(b)

Fig 7. The mixture of rice husk and products after the reaction, using: (a) $\mathrm{MnCl}_{2} \cdot \mathrm{H}_{2} \mathrm{O}$ and (b) $\mathrm{MnOx} / \mathrm{Hi}$ ZZSM5 as a catalyst
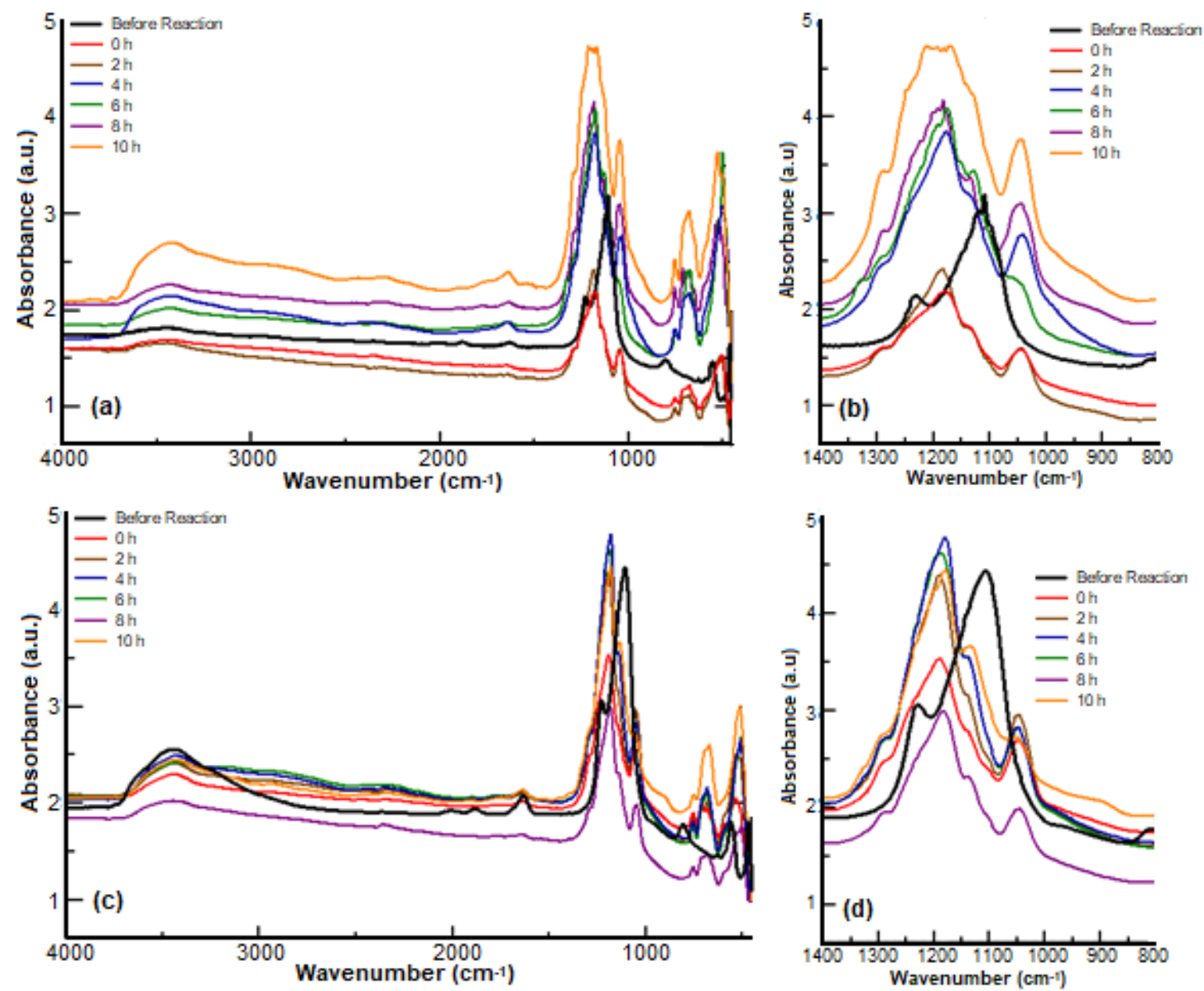

Fig 8. FTIR Study on fresh and used ZSM-5 catalysts: (a-b) MnOx/Mi_ZSM-5, and (c-d) MnOx/Hi_ZSM-5 


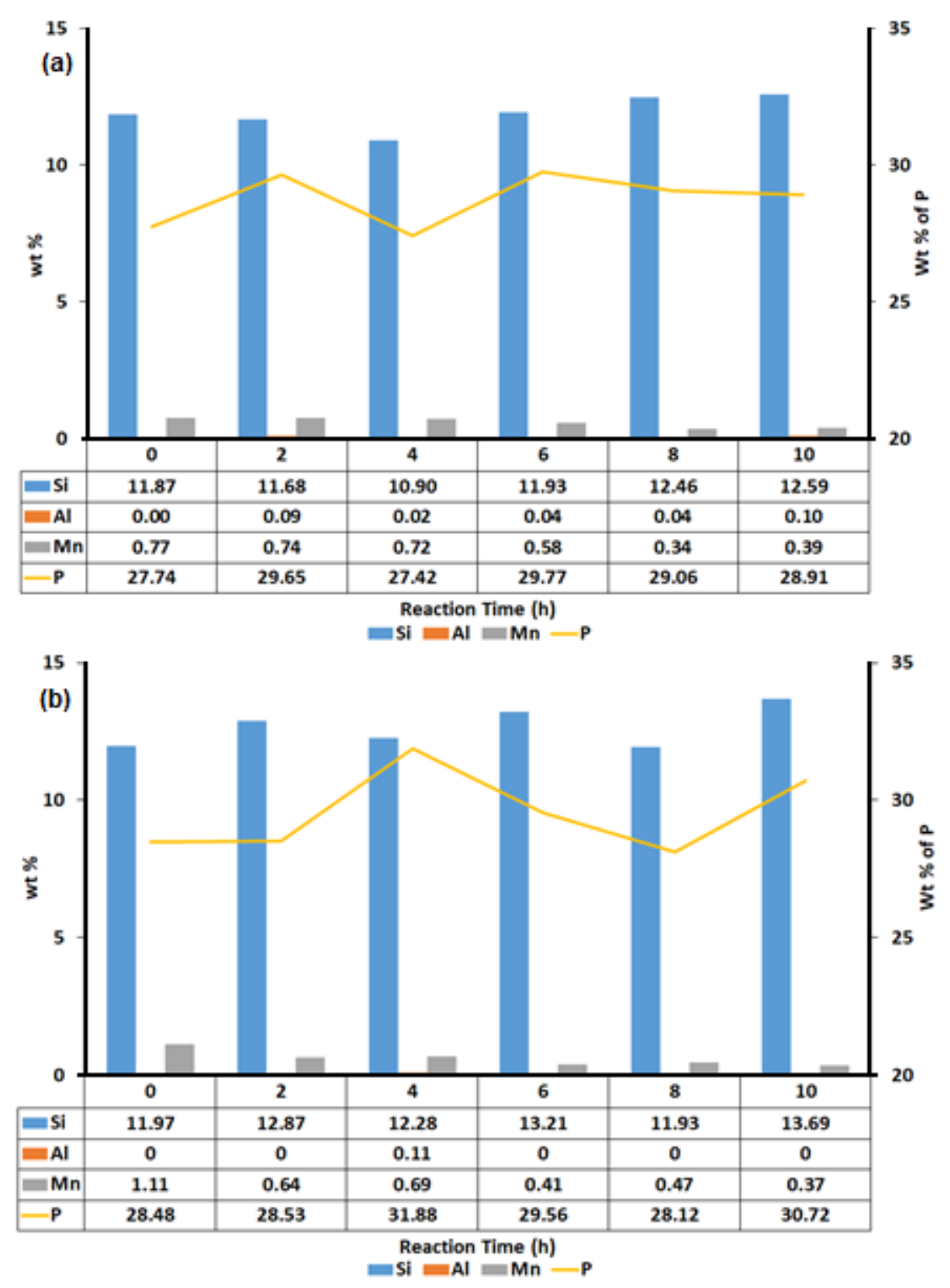

Fig 9. Elemental analysis of MnOx/ZSM-5 catalysts after being used in the reaction: (a) MnOx/Mi_ZSM-5, (b) MnOx/Hi_ZSM-5. In fresh catalysts: MnOx/Mi_ZSM-5 (Si 43\%, Al 1.39\%, Mn 1.97\%); MnOx/Hi_ZSM-5 (Si 44.7\%, Al 1.7\%, Mn 1.91\%), P was not detected. For all measurement, $\mathrm{O}$ was added to obtain $100 \%$ of weight (not shown)

MnOx/Hi_ZSM-5 catalyst. Meanwhile, the reaction on Hi_ZSM-5 also give the optimum reaction for $8 \mathrm{~h}$ but the $\%$ yield (7.64\%). On the other hand, the reaction with MnOx/Mi_ZSM-5 has given high \%Y of LA, $12.6 \%$, after $10 \mathrm{~h}$ reaction time. The reaction using $\mathrm{MnCl}_{2} \cdot 4 \mathrm{H}_{2} \mathrm{O}$ as a catalyst has an optimum reaction after $8 \mathrm{~h}$, giving $\%$ yield of $8.86 \%$, before decreased after $10 \mathrm{~h}$. However, it is also observed that thick charcoal was also found as a product (Fig. 7). This indicates the contribution of zeolites as catalyst supports. In case of HMF production reported by Chen et al. [12] at $100{ }^{\circ} \mathrm{C}$, the $\%$ yield was $0.1 \%$ that might be further converted to Levulinic acid, as observed in this work with the same reaction condition. This work has proven the benefit of using a heterogeneous catalyst in two aspects; first, the reaction temperature can be lowered from 200 to $100^{\circ} \mathrm{C}$, and second, the catalyst can be easily separated from the product. Moreover, the used of mineral acids (e.g. $\mathrm{H}_{2} \mathrm{SO}_{4}, \mathrm{HCl}$ ) which are associated 
with the environmental issues, corrosion and toxicity could be eliminated.

\section{Stability Test of Catalysts}

The stability of MnOx/Mi_ZSM-5 and MnOx/Hi_ZSM-5 after the reaction was studied before and after reaction using FTIR and EDX. Overall in the range of $4000-400 \mathrm{~cm}^{-1}$ wavenumber, Fig. 8(a) and 8(c) show that the characteristic peaks for used MnOx/ZSM-5 catalysts after reaction are similar with the initial peak before reaction (fresh catalysts), although the intensity of hydrogen-bonded -OH symmetry from silanol (the broad bands at $3600-3000 \mathrm{~cm}^{-1}$ ) was increased and $\mathrm{H}-\mathrm{O}-\mathrm{H}$ bending vibration at $1620 \mathrm{~cm}^{-1}$ are decreased. Closer observation on the peaks in $1400-900 \mathrm{~cm}^{-1}$ shows that the peaks assigned to $\mathrm{Si}-\mathrm{O}-\mathrm{Al}$ rings in the zeolite framework [22-23] have been altered. The peak that attributed to AlO from alumina [24] appeared, and the intensity increased along with the reaction time. Even after the catalysts were introduced to the reaction condition $(\mathrm{pH}$ $\sim 2,373 \mathrm{~K})$ before started $(0 \mathrm{~h})$, the alteration of the infrared spectra was observed. It is suggested that hydrolysis of Al-O-Si bond occurring due to acidic reaction condition ( $\mathrm{pH} \sim 2)$ and high reaction temperature, which leads to a decrease of Bronsted acidity $\left(\mathrm{Si}-\mathrm{O}\left(\mathrm{H}^{+}\right)-\mathrm{Al}\right)$. From these findings, the contribution of silanol groups, as well as the pore size of zeolites, should also be considered.

From EDX analysis (Fig. 9), both micro- and hierarchical MnOx/ZSM-5 were suffered from severe dealumination. Desilication (> 50\% of Si removed) also occurred since $0 \mathrm{~h}\left(100{ }^{\circ} \mathrm{C}\right.$, acidic condition), then stabilized until $10 \mathrm{~h}$ reaction time. Moreover, the $\%$ of $\mathrm{Mn}$ was also decreased, indicative of the removal of $\mathrm{Mn}$ (II) from the MnOx/ZSM-5 structure during the reaction taking place. This process suggests that in conversion using MnOx/ZSM-5 zeolites as a catalyst, the interaction of both solid $\mathrm{MnOx}$ (as the active site in ZSM-5) and aqueous $\mathrm{Mn}^{2+}$ ions (in the solution) with $\mathrm{H}_{2} \mathrm{O}_{2}$ to create $\mathrm{HO}$ - radicals (in Fenton-like system) took place. Furthermore, some of the phosphorus (from the phosphoric acid that added prior to the reaction started) were found in the used catalyst. However, since the number of used catalysts was too small, XRD measurement to analyze the structure cannot be conducted.

\section{- CONCLUSION}

It is concluded that hierarchical ZSM5 was successfully synthesized, having added mesoporous features to the structure, compared to that of the microporous ZSM-5. The optimum reaction time was 8 $\mathrm{h}$, in which conversion with hierarchical MnOx/ZSM-5 catalyst gave the highest amount of levulinic acid (\%Y of $15.83 \%$ ), followed by $\mathrm{MnOx} / \mathrm{Mi} Z \mathrm{ZSM}-5$ (\%Y of 9.93\%). Finally, it can be concluded the conversion took place as the interaction between the cellulose and either $\mathrm{MnOx}$ in zeolites or $\mathrm{Mn}^{2+}$ ions in the solution, with the support of porous ZSM-5 framework. Hierarchical system somehow helps the ZSM-5 structure stays intact.

\section{- ACKNOWLEDGMENTS}

This research is funded by TWAS 2013 (13-034 RG/CHE/AS_I- UNESCO FR: 3240277703), International Collaboration Grant 2013-2014 from Universitas Indonesia and PUPT BOPTN 2015-2017 from MoRTHE. Prof. H. Yoshida and Dr. J. Gunlazuardi are greatly acknowledged for access to XRD measurement at the University of Kyoto.

\section{- REFERENCES}

[1] Fukuoka, A., and Dhepe, P.L., 2006, Catalytic conversion of cellulose into sugar alcohols, Angew. Chem., 45 (31), 5161-5163.

[2] Corma, A., Huber, G.W., Sauvanaud, L., and O'Connor, P., 2007, Processing biomass-derived oxygenates in the oil refinery: Catalytic cracking (FCC) reaction pathways and role of catalyst, $J$. Catal., 247 (2), 307-327.

[3] Wang, L., Zhang, Z., Yin, C., Shan, Z., and Xiao, F.S., 2010, Hierarchical mesoporous zeolites with controllable mesoporosity templated from cationic polymers, Microporous Mesoporous Mater., 131 (13), 58-67.

[4] Hendriks, A., and Zeeman, G., 2009, Pretreatments to enhance the digestibility of lignocellulosic biomass: A review, Bioresour. Technol., 100 (1), 10-18. 
[5] Bozell, J.J., Moens, L., Elliott, D.C., Wang, Y., Neuenscwander, G.G., Fitzpatrick, S.W., Bilski, R.J., and Jarnefeld, J.L., 2000, Production of levulinic acid and use as a platform chemical for derived products, Resour. Conserv. Recycl., 28 (3-4), 227-239.

[6] Sun, Y., and Cheng, J., 2002, Hydrolysis of lignocellulosic materials for ethanol production: A review, Bioresour. Technol., 83 (1), 1-11.

[7] Kobayashi, H., Ohta, H., and Fukuoka, A., 2012, Conversion of lignocellulose into renewable chemicals by heterogeneous catalysis, Catal. Sci. Technol., 2 (5), 869-883.

[8] Dhepe, P.L., and Fukuoka, A., 2008, Cellulose conversion under heterogeneous catalysis, ChemSusChem, 1 (12), 969-975.

[9] Wettstein, S.G., Bond, J.Q., Alonso, D.M., Pham, H.N., Datye, A.K., and Dumesic, J.A., 2012, RuSn bimetallic catalysts for selective hydrogenation of levulinic acid to $\gamma$-valerolactone, Appl. Catal., B, 117118, 321-329.

[10] Pasquale, G., Vázquez, P., Romanelli,G., and Baronetti, G., 2012, Catalytic upgrading of levulinic acid to ethyl levulinate using reusable silica-included Wells-Dawson heteropolyacid as catalyst, Catal. Commun., 18, 115-120.

[11] Rackemann, D.W., and Doherty,W.O.S., 2011, The conversion of lignocellulosics to levulinic acid, Biofuels, Bioprod. Biorefin., 5 (2), 198-214.

[12] Chen, Y., Li, G., Yang, F., and Zhang, S.M., 2011, Mn/ZSM-5 participation in the degradation of cellulose under phosphoric acid media, Polym. Degrad. Stab., 96 (5), 863-869.

[13] Krisnandi, Y.K., Putra, B.A.P., Bahtiar, M., Abdullah, I., and Howe, R.F., 2015, Partial oxidation of methane to methanol over heterogeneous catalyst Co/ZSM-5, Procedia Chem., 14, 508-515.

[14] Dence, C.W. 1992, "The Determination of Lignin" in Methods in Lignin Chemistry, Lin, S.Y., and Dence, C.W., (eds.), Springer-Verlag, Heidelberg, Germany, 33-61.
[15] The ASTM International standard D1104-46, 1978, Method of test for Holocellulose in Wood.

[16] The ASTM International standard D1103-60, 1978, Method of test for Alpha-cellulose in Wood.

[17] Taherzadeh, M.J., and Karimi, K., 2008, Pretreatment of lignocellulosic wastes to improve ethanol and biogas production: A review, Int. J. Mol. Sci., 9 (9), 1621-1651.

[18] Krisnandi, Y.K., Samodro, B.A., Sihombing, R., and Howe, R.F., 2015, Direct synthesis of methanol by partial oxidation of methane with oxygen over cobalt modified mesoporous H-ZSM-5 catalyst, Indones. J. Chem., 15 (3), 263-268.

[19] Treacy, M.M.J., and Higgins, J.B., 2001, Collection of Simulated XRD Powders for Zeolites, $4^{\text {th }}$ rev. ed., Elsevier Science B.V.

[20] Zhou, M., Rownaghi, A.A., and Hedlund, J., 2013, Synthesis of mesoporous ZSM-5 zeolite crystals by conventional hydrothermal treatment, RSC Adv., 3 (36), 15596-15599.

[21] Wang, D., Liu, Z., Wang, H., Xie, Z., and Tang, Y., 2010, Shape-controlled synthesis of monolithic ZSM-5 zeolite with hierarchical structure and mechanical stability, Microporous Mesoporous Mater.,132 (3), 428-434.

[22] Hassaninejad-Darzi, S.K., 2015, Fabrication of a non-enzymatic Ni(II) loaded ZSM-5 nanozeolite and multi-walled carbon nanotubes paste electrode as a glucose electrochemical sensor, RSC $A d v$., 5, 105707-105718.

[23] Karge, H.G., Verified Syntheses of Zeolitic Materials, Characterization by IR Spectroscopy, $2^{\text {nd }}$ Revised Edition, http://www.iza-online.org/synthesis/VS_ 2ndEd/IR_Spectroscopy.htm, accessed on 28 January 2018.

[24] Rohayati, Krisnandi, Y.K., and Sihombing, R., 2017, Synthesis of ZSM-5 zeolite using Bayat natural zeolite as silica and alumina source, AIP Conf. Proc., 1862, 030094. 